\title{
Low skeletal muscle density is associated with poor survival in patients who receive chemotherapy for metastatic gastric cancer
}

\author{
NAOMI HAYASHI ${ }^{1,2}$, YUICHI ANDO ${ }^{2}$, BISHAL GYAWALI $^{2}$, TOMOYA SHIMOKATA $^{2}$, OSAMU MAEDA ${ }^{2,3}$, \\ MASAHIDE FUKAYA $^{4}$, HIDEMI GOTO ${ }^{3}$, MASATO NAGINO ${ }^{4}$ and YASUHIRO KODERA ${ }^{1}$ \\ ${ }^{1}$ Department of Gastroenterological Surgery, Nagoya University Graduate School of Medicine, Nagoya 466-8550; \\ ${ }^{2}$ Department of Clinical Oncology and Chemotherapy, Nagoya University Hospital, Nagoya 466-8550; \\ Departments of ${ }^{3}$ Gastroenterology and Hepatology and ${ }^{4}$ Surgical Oncology, \\ Nagoya University Graduate School of Medicine, Nagoya 466-8550, Japan
}

Received September 3, 2015; Accepted November 13, 2015

DOI: 10.3892/or.2015.4475

\begin{abstract}
Low skeletal muscle density (SMD) and low skeletal muscle index (SMI) are associated with poor overall survival (OS) in patients with various types of cancer. We retrospectively studied SMD and SMI using computed tomographic (CT) scans in patients with gastric cancer receiving chemotherapy to evaluate its prognostic significance. SMD and SMI were obtained from CT-based analysis using Slice-O-Matic ${ }^{\circledR}$ medical imaging software in patients who received S-1 plus cisplatin chemotherapy for metastatic gastric cancer. The CT images taken within 1 month before starting chemotherapy were used. The cut-off values for determining low SMD $[<33$ Hounsfield units (HU) in obese and $<41 \mathrm{HU}$ in non-obese patients] and low SMI $\left(<41 \mathrm{~cm}^{2} / \mathrm{m}^{2}\right.$ in females, $<43 \mathrm{~cm}^{2} / \mathrm{m}^{2}$ in non-obese males and $<53 \mathrm{~cm}^{2} / \mathrm{m}^{2}$ in obese males) were referenced from a large population based study. The CT images of 53 patients were reviewed. The median SMD was 36.8 HU (range, 19.5-59.3 HU), and the median SMI was $39.8 \mathrm{~cm}^{2} / \mathrm{m}^{2}$ (range, $23.7-60.0 \mathrm{~cm}^{2} / \mathrm{m}^{2}$ ). Patients with low SMD had significantly shorter OS compared with patients having normal SMD (8.9 vs. 12.8 months, $\mathrm{P}=0.03)$. However, OS did not differ significantly between patients with low and normal SMI (11.1 and 14.3 months, $\mathrm{P}=0.18$ ). Multivariate analyses confirmed that low SMD was an independent predictor of poor outcomes $(\mathrm{P}<0.01)$. SMD is an important prognosticator of survival in patients with metastatic gastric cancer receiving chemotherapy.
\end{abstract}

\footnotetext{
Correspondence to: Dr Naomi Hayashi, Department of Clinical Oncology and Chemotherapy, Nagoya University Graduate School of Medicine, 65 Tsurumai-cho, Showa-ku, Nagoya 466-8550, Japan E-mail: naomi-hayashi@med.nagoya-u.ac.jp
}

Key words: skeletal muscle density, skeletal muscle index, sarcopenia, prognostic factor, gastric cancer, chemotherapy

\section{Introduction}

The role of skeletal muscle as a prognostic and predictive factor in cancer management has been a topic of interest lately (1-6). In particular, two skeletal muscle parameters have been studied in detail: skeletal muscle density (SMD) and skeletal muscle index (SMI). SMD reflects the lipid content of the muscle: the higher the lipid content, the lower the SMD and the weaker the muscle strength (7-9). SMI reflects the skeletal muscle volume or mass and is measured as skeletal muscle area divided by the square of the body height.

Both SMD and SMI have been shown to predict survival in patients with various types of cancer $(10,11)$. Low SMI, also known as sarcopenia, is also a predictor of severe toxicities associated with anticancer drugs such as 5 -fluorouracil and sorafenib $(12,13)$. However, this association of SMD and/or SMI with prognosis or treatment-toxicities among gastric cancer patients has not been studied yet.

The clinical significance of SMD and SMI in patients with gastric cancer may differ from that in patients with other types of cancer owing to differences in dietary status caused by gastrectomy, gastrointestinal disorders, or both. Because chemotherapy is the only treatment for metastatic gastric cancer and has only limited survival benefit (14), it is important to have factors that could effectively predict the prognosis or adverse effects for proper assessment of risk-benefit ratio to the patients. Hence, we undertook this study to evaluate the prognostic implications of SMD and SMI in patients with metastatic gastric cancer receiving chemotherapy.

\section{Materials and methods}

Patients. Patients with recurrent or metastatic gastric cancer who received S-1 plus cisplatin as first-line chemotherapy in Nagoya University Hospital (Nagoya, Japan) from January 2009 through June 2014 were studied retrospectively. All but 2 patients received S-1 $\left(80 \mathrm{mg} / \mathrm{m}^{2}\right.$ on days 1-21) orally and cisplatin $\left(60 \mathrm{mg} / \mathrm{m}^{2}\right.$ on day 8$)$ intravenously every 5 weeks. The other 2 patients received S-1 $\left(80 \mathrm{mg} / \mathrm{m}^{2}\right.$ on days $\left.1-14\right)$ orally and cisplatin $\left(60 \mathrm{mg} / \mathrm{m}^{2}\right.$ on day 1$)$ intravenously every 3 weeks. All patients had histologically proven adenocarcinoma 
of stomach with at least one metastatic lesion as confirmed by diagnostic imaging. CT scanning was performed every 2 months in most patients to evaluate treatment response. Patients with double primary cancers were excluded. This retrospective study was conducted after receiving formal approval from our Institutional Review Board.

Data collection. Clinical data were extracted from the hospital electronic medical database and included the following variables: age, gender, ECOG performance status (PS), height (m), body weight $(\mathrm{kg})$, at baseline (before starting chemotherapy), history of gastrectomy, histopathological characteristics of primary tumor (well or poorly differentiated), and subsequent treatments, including conversion surgery. Relative dose intensity (RDI) was calculated by dividing the actual total dose intensity (actual total dose divided by the duration of therapy) by the planned total dose intensity (planned total dose divided by the planned duration of therapy).

Skeletal muscle assessment. Baseline CT images obtained within 1 month before starting chemotherapy were used to evaluate SMD and SMI. Skeletal muscle area at the level of the third lumber vertebra (L3) scan was quantified by using SliceO-Matic ${ }^{\circledR}$ medical imaging software (version 5.0; TomoVision, Magog, Quebec, Canada) using a Hounsfield unit (HU) threshold of -29 to +150 for identification as has been described previously (15) (Fig. 1). The skeletal muscle area thus obtained was divided by the square of body height to get the skeletal muscle index (SMI) in the units of $\mathrm{cm}^{2} / \mathrm{m}^{2}$. The value for the skeletal muscle density (SMD) in HU at the same level was also obtained from the software. It is estimated that SMD decreases by $1 \mathrm{HU}$ for each additional $1 \mathrm{~g} / 100 \mathrm{ml}$ lipid in muscle (8). The cut-off values for determining low SMD and low SMI were based on a recently published population-based study of 1,473 patients (10) (Table I). Although various cut-offs for diag-
Table I. Cut-off values of SMD and SMI.

\begin{tabular}{llllll}
\hline & \multicolumn{2}{c}{ SMD $(\mathrm{HU})$} & & \multicolumn{2}{c}{$\mathrm{SMI}\left(\mathrm{cm}^{2} / \mathrm{m}^{2}\right)$} \\
\cline { 2 - 3 } BMI $\left(\mathrm{kg} / \mathrm{m}^{2}\right)$ & Male & Female & & Male & Female \\
\hline$<20.0$ & $<41$ & $<41$ & & $<43$ & $<41$ \\
20.0 to 24.9 & $<41$ & $<41$ & & $<43$ & $<41$ \\
$\geq 25.0$ & $<33$ & $<33$ & & $<53$ & $<41$
\end{tabular}

SMD, skeletal muscle density; BMI, body mass index; SMI, skeletal mass index; HU, Hounsfield units. Reproduced from Martin et al with permission (10).

nosing sarcopenia have been proposed, this criteria takes into account both gender and BMI, and therefore is more reliable.

Statistical analysis. Overall survival (OS), progression-free survival (PFS), and tumor response (evaluated according to the Response Evaluation Criteria in Solid Tumors, version 1.0) were compared between patients with low SMD and those with normal SMD, as well as between patients with low SMI and those with normal SMI. Briefly, OS was defined as the time from the day of starting chemotherapy to the day of death or the last contact, and PFS was defined as the time from the day of starting chemotherapy to the day on which the first event of disease progression was diagnosed or the day of death from any cause. PFS and OS with $95 \%$ confidence intervals $(95 \% \mathrm{CI})$ were estimated by the Kaplan-Meier method and were compared between groups by the log-rank test. Data on patients who were alive or lost to follow-up were censored in the calculation of OS. Data on patients who discontinued chemotherapy because of adverse events or who could not be followed up until disease progression were censored in the calculation of PFS. Associations of the

A

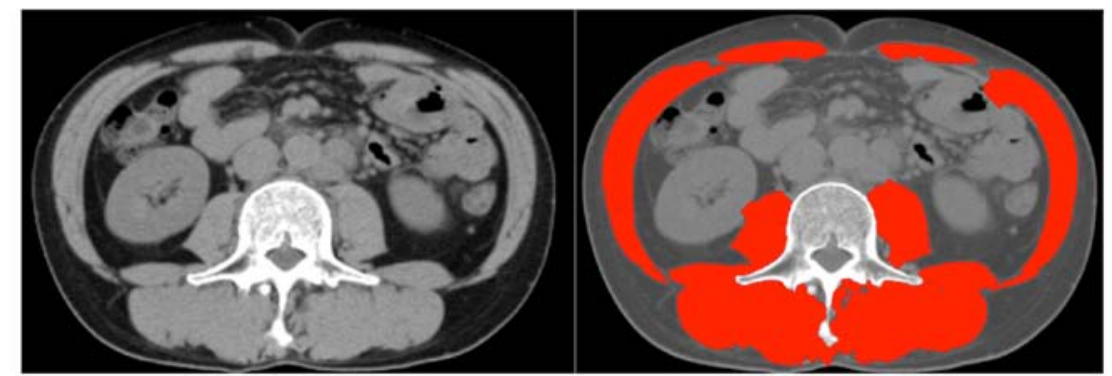

B

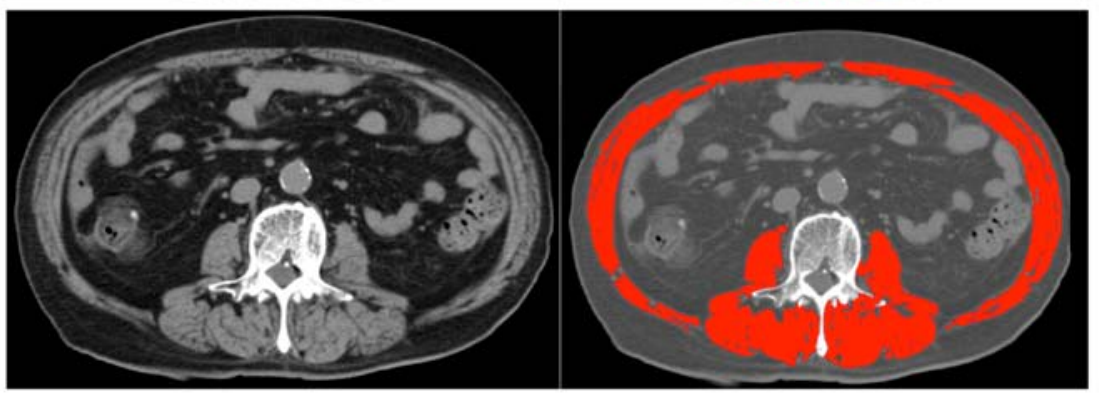

Figure 1. CT images using Slice-O-Matic ${ }^{\circledast}$ medical imaging software. Representative abdominal CT images obtained at the third lumbar vertebra (L3) before and after analyses performed using Slice-O-Matic ${ }^{\circledast}$ medical imaging software. Red zone indicates the muscle area identified using a Hounsfield unit (HU) threshold of -29 to +150 . Both patient (A) and patient (B) had similar SMI values (43.8 and $42.7 \mathrm{~cm}^{2} / \mathrm{m}^{2}$, respectively), but the former had a higher SMD (50.4 HU) than the latter (19.5 HU). 
Table II. Patient characteristics.

\begin{tabular}{|c|c|c|c|c|c|c|}
\hline \multirow[b]{2}{*}{ Variable } & \multicolumn{2}{|c|}{ SMD (HU) } & \multirow[b]{2}{*}{$\mathrm{P}$-value } & \multicolumn{2}{|c|}{$\operatorname{SMI}\left(\mathrm{cm}^{2} / \mathrm{m}^{2}\right)$} & \multirow[b]{2}{*}{$\mathrm{P}$-value } \\
\hline & $\begin{array}{c}\text { Low }(\mathrm{n}=31) \\
\mathrm{n}(\%)\end{array}$ & $\begin{array}{c}\text { Normal }(n=22) \\
n(\%)\end{array}$ & & $\begin{array}{c}\text { Low }(\mathrm{n}=37) \\
\mathrm{n}(\%)\end{array}$ & $\begin{array}{c}\text { Normal }(\mathrm{n}=16) \\
\mathrm{n}(\%)\end{array}$ & \\
\hline \multicolumn{7}{|l|}{ Age (years) } \\
\hline Median & 68 & 60.5 & \multirow{2}{*}{$<0.01$} & 66 & 63.5 & \multirow[t]{2}{*}{0.71} \\
\hline Range & $44-80$ & $33-80$ & & $33-80$ & $44-80$ & \\
\hline \multicolumn{7}{|l|}{ Gender } \\
\hline Male & $17(54.8)$ & $16(72.7)$ & \multirow[t]{2}{*}{0.90} & $19(51.1)$ & $14(87.5)$ & \multirow[t]{2}{*}{$0.01^{\mathrm{a}}$} \\
\hline Female & $14(45.2)$ & $6(27.2)$ & & $18(48.6)$ & $2(12.5)$ & \\
\hline \multicolumn{7}{|l|}{ PS } \\
\hline 0 to 1 & $27(87.1)$ & $19(86.3)$ & \multirow[t]{2}{*}{0.94} & $32(86.4)$ & $14(87.5)$ & \multirow[t]{2}{*}{0.23} \\
\hline 2 & $4(12.9)$ & $3(13.6)$ & & $5(13.5)$ & $2(12.5)$ & \\
\hline \multicolumn{7}{|l|}{ Gastrectomy } \\
\hline Yes & $22(70.9)$ & $12(54.5)$ & \multirow[t]{2}{*}{0.21} & $26(70.2)$ & $8(50.0)$ & \multirow[t]{2}{*}{0.23} \\
\hline No & $9(29.1)$ & $10(45.4)$ & & $11(29.7)$ & $8(50.0)$ & \\
\hline \multicolumn{7}{|l|}{ Differentiation } \\
\hline Well & $10(32.2)$ & $4(18.2)$ & \multirow[t]{2}{*}{0.25} & $11(29.7)$ & $3(18.8)$ & \multirow[t]{2}{*}{0.40} \\
\hline Moderate to poor & $21(67.7)$ & $18(81.8)$ & & $26(70.2)$ & $13(81.3)$ & \\
\hline \multicolumn{7}{|c|}{ No. of metastatic site } \\
\hline$<2$ & $25(80.6)$ & $17(77.3)$ & \multirow[t]{2}{*}{0.77} & $28(75.7)$ & $14(87.5)$ & \multirow[t]{2}{*}{0.33} \\
\hline$\geq 2$ & $6(19.3)$ & $5(22.7)$ & & $9(24.3)$ & $2(12.5)$ & \\
\hline \multicolumn{7}{|l|}{ Conversion surgery } \\
\hline Yes & $6(19.3)$ & $2(9.1)$ & \multirow[t]{2}{*}{0.30} & $3(8.1)$ & $5(31.5)$ & \multirow[t]{2}{*}{$0.03^{\mathrm{a}}$} \\
\hline No & $25(80.6)$ & $20(90.9)$ & & $34(91.9)$ & $11(68.8)$ & \\
\hline \multicolumn{7}{|l|}{ SMD } \\
\hline Median & 30.8 & 44.8 & $<0.01^{\mathrm{a}}$ & 36.8 & 37.5 & 0.59 \\
\hline \multicolumn{7}{|l|}{ SMI } \\
\hline Median & 39.8 & 41.7 & 0.45 & 36.1 & 48.2 & $<0.01^{\mathrm{a}}$ \\
\hline
\end{tabular}

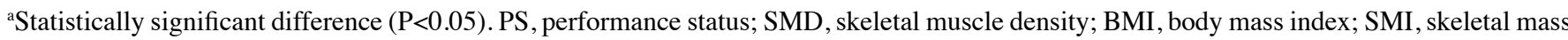
index; HU, Hounsfield units.

following variables with OS were analyzed with the use of multivariate Cox hazard models: SMD (normal vs. low), SMI (normal vs. low), gender (male vs. female), PS (0-1 vs. 2), age (less than or equal to the median vs. higher than the median), number of metastatic sites (less than 2 vs. 2 or more), and tumor response to first-line chemotherapy (yes vs. no). P-values $<0.05$ were considered to indicate statistical significance. P-values are estimated from one-sided tests. Statistical analysis was performed using JMP software (version 9; SAS Institute Inc., Cary, NC, USA).

\section{Results}

Patient characteristics. A total of 53 patients were included in this study (Table II). The median SMD was $36.8 \mathrm{HU}$ (range, 19.5-59.3 HU), and the median SMI was $39.8 \mathrm{~cm}^{2} / \mathrm{m}^{2}$ (range, 23.7-60.0 $\left.\mathrm{cm}^{2} / \mathrm{m}^{2}\right)$. Thirty-one patients $(58.5 \%)$ had low SMD (median, $30.8 \mathrm{HU}$ ) and 37 patients $(69.8 \%$ ) had low SMI (median, $36.1 \mathrm{~cm}^{2} / \mathrm{m}^{2}$ ). The distribution of the 34 patients $(64.1 \%)$ who had undergone gastrectomy before starting chemotherapy was balanced between low and normal groups of both SMD or SMI. There was no significant difference in RDI between the patients with low SMD and those with normal SMD (cisplatin, $\mathrm{P}=0.77 ; \mathrm{S}-1, \mathrm{P}=0.83$ ) or between patients with low SMI and those with normal SMI (cisplatin, $\mathrm{P}=0.89$; $\mathrm{S}-1$, $\mathrm{P}=0.86$ ). There was a numerically higher incidence of grade 3 or higher neutropenia in the patients with low SMI than in those with normal SMI (35.1 vs. $18.8 \%, \mathrm{P}=0.22)$.

Overall survival. The median OS of the 53 patients was 11.7 months (95\% CI, 8.2 to 13.2 months). Patients with low SMD had significantly shorter OS (8.9 months; 95\% CI, 7.7 to 12.8 months) compared with patients with normal SMD (12.8 months; 95\% CI, 10.1 to 37.0 months, $\mathrm{P}=0.03$ ) (Fig. 2A). On the other hand, median OS was similar between patients with low SMI and normal SMI (11.1 vs. 14.3 months, $\mathrm{P}=0.18$ ) (Fig. 2B).

Progression-free survival. The median PFS of the 53 patients was 4.8 months (95\% CI, 3.2 to 6.7 months). Median PFS 
A

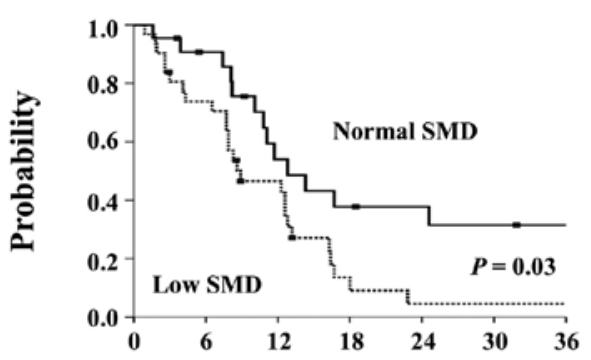

Number at risk

\begin{tabular}{clllllll}
\hline Normal & 22 & 18 & 10 & 7 & 6 & 5 & 4 \\
Low & 31 & 22 & 12 & 2 & 1 & 1 & 1 \\
\hline
\end{tabular}

B

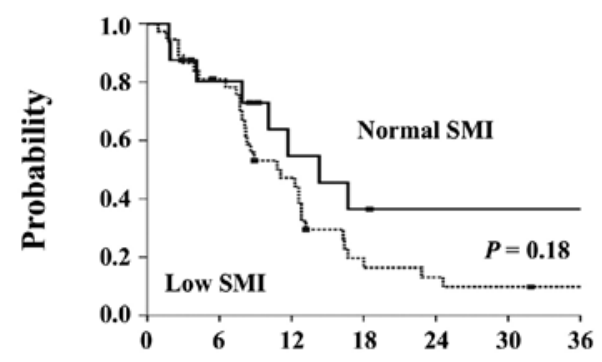

Number at risk

\begin{tabular}{cccccccc}
\hline Normal & 16 & 11 & 6 & 4 & 3 & 2 & 2 \\
Low & 37 & 29 & 16 & 5 & 4 & 3 & 2 \\
\hline
\end{tabular}

Figure 2. Overall survival (OS) curves of patients with low or normal SMD (A) and those with low or normal SMI (B). OS differed significantly between patients with low SMD and those with normal SMD ( $\mathrm{P}=0.03)$, but did not differ between patients with low SMI and those with normal SMI $(\mathrm{P}=0.18)$.

A

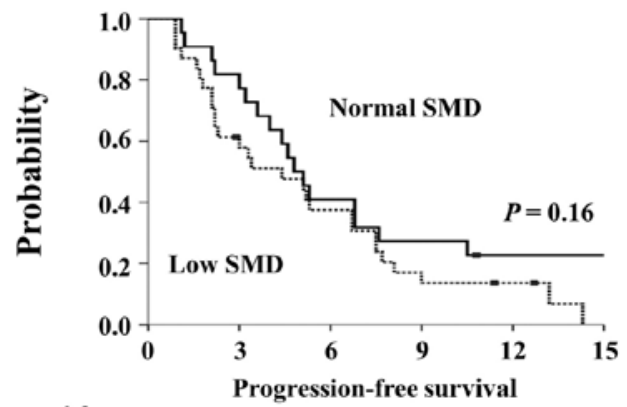

Number at risk

\begin{tabular}{ccccccc} 
Number at risk & & & & & & \\
\hline Normal & 22 & 17 & 9 & 6 & 4 & 4 \\
Low & 31 & 17 & 11 & 4 & 3 & 0 \\
\hline
\end{tabular}

B

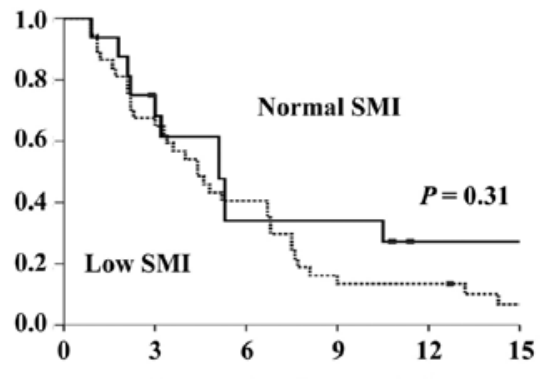

Progression-free survival

\begin{tabular}{ccccccc} 
Number at risk & \multicolumn{7}{c}{ Progression-free survival } \\
\hline Normal & 16 & 10 & 5 & 5 & 2 & 2 \\
Low & 37 & 24 & 15 & 5 & 5 & 2 \\
\hline
\end{tabular}

Figure 3. Progression-free survival (PFS) curves of patients with low or normal SMD (A) and those with low or normal SMI (B). PFS was not associated with either SMD or SMI.
Table III. Multivariate Cox proportional-hazards model for survival.

\begin{tabular}{lccc}
\hline Variable & HR & $95 \%$ CI & P-value \\
\hline SMD & & & $<0.01^{\mathrm{a}}$ \\
$\quad$ Normal & Ref & $0.17-0.76$ & \\
Low & 2.72 & $1.32-5.82$ & \\
SMI & & & 0.98 \\
$\quad$ Normal & Ref & $0.42-2.57$ & \\
Low & 1.01 & $0.39-2.38$ & \\
PS & & & $0.02^{\mathrm{a}}$ \\
0 to 1 & Ref & $0.13-0.83$ & \\
2 & 3.25 & $1.21-7.88$ & \\
Age (years) & & & 0.10 \\
$\leq 65$ & Ref & $0.24-1.14$ & \\
$>65$ & 1.91 & $0.87-4.21$ & \\
Gender & & & 0.13 \\
Male & & & \\
Female & Ref & $0.81-4.97$ & \\
No. of metastatic site & 0.51 & $0.20-1.23$ & \\
$<2$ & & & $0.03^{\mathrm{a}}$ \\
$\geq 2$ & Ref & $0.18-0.89$ & \\
Response to first-line therapy & & & $<0.01^{\mathrm{a}}$ \\
Yes & Ref & $0.08-0.60$ & \\
No & 4.25 & $1.65-11.6$ & \\
\hline
\end{tabular}

aStatistically significant difference $(\mathrm{P}<0.05)$. SMD, skeletal muscle density; SMI, skeletal mass index; PS, performance status; HR, hazard ratio.

did not differ significantly between patients with low SMD and those with normal SMD (4.4 vs. 4.9 months, $\mathrm{P}=0.16$ ) or between patients with low SMI and those with normal SMI (4.4 vs. 5.1 months, $\mathrm{P}=0.31$ ) (Fig. 3).

Tumor response. Among the 53 patients, 2 patients had a complete response, 12 had a partial response, and 18 had stable disease. The response rate was $26.4 \%$, and the disease control rate was $60.4 \%$. The response rate was similar in patients with low SMD (29.0\%) and those with normal SMD (22.7\%). On the other hand, there was a trend toward a lower response rate in the patients with low SMI (18.9\%) than in those with normal SMI $(43.5 \%, \mathrm{P}=0.06)$.

Multivariate analysis. Multivariate analysis confirmed that low SMD was an independent predictor of poor outcomes; the hazard ratio (HR) for death in patients with low SMD versus those with normal SMD was 2.72 (95\% CI, 1.32 to 5.82; $\mathrm{P}<0.01$; Table III). The other independent predictors of poor OS included a PS of 2 (HR, 3.25; 95\% CI, 1.21 to 7.88; $\mathrm{P}=0.02)$, two or more metastatic sites of disease (HR, 2.48; 95\% CI, 1.13 to 5.55; $\mathrm{P}=0.03$ ), and no response to first-line therapy (HR, 4.18; 95\% CI, 1.65 to $11.6 ; \mathrm{P}<0.01)$. 


\section{Discussion}

This is the first study to demonstrate that low SMD is an independent poor prognostic factor in metastatic gastric cancer patients receiving chemotherapy. Also, in contrast to reports of other cancers, our study showed that sarcopenia or low SMI is not associated with prognosis in metastatic gastric cancer. On the other hand, PFS and tumor response were not associated with either SMD or SMI in this study. These findings imply that low SMD, is an important prognostic indicator in patients with gastric cancer who are considered eligible for systemic chemotherapy, but is not a predictor of the response to chemotherapy.

The association of SMD, but not SMI, with survival outcomes in our present study is an intriguing finding. One plausible explanation for this could be that the increase in lipid content of muscle occurs before the decline in muscle mass and therefore, the decrease in SMD is detected earlier than the decrease in SMI. Also, CT based calculation allows for early detection of fall in HU (SMD) while the muscle area remains unchanged; thus decrease in SMD is detected earlier than corresponding decrease in SMI. Because most of the previous studies have examined either SMD or SMI only, this discrepancy has not yet been revealed in those studies. Second, many gastric cancer patients will have undergone gastrectomy as a part of their treatment. Gastrectomy, in itself, has been known to decrease muscle mass (16). Abdiev et al reported that after gastrectomy the skeletal muscle mass decreased to around $85 \%$ of preoperative level (17). Therefore, the low SMI found among patients in this study could have partly been an effect of gastrectomy. These results suggest that SMD would better facilitate assessment of the risk-benefit ratio of systemic chemotherapy in metastatic gastric cancer patients compared to SMI.

PFS, tumor response and toxicities were not related to SMD or SMI in this study. Nevertheless, both tumor response and toxicities were numerically better in normal SMI group versus low SMI group.

Some other studies in patients with diseases such as breast cancer or renal cell carcinoma have also reported that lower SMI may be linked to severe toxicities, leading to dose reduction and then to a shorter time to progression $(12,13)$. The clinical value of skeletal muscle assessment is thus considered to warrant further investigation in gastric cancer patients.

Our study had several important limitations. It was retrospective and had a small sample size. In addition, the cut-off values that we used for SMD and SMI were based on the results of a study done in a Western population (10), because there is no clear consensus about the Asian-specific cut-off values of SMD and SMI.

In conclusion, our results demonstrated that low skeletal muscle density, rather than low skeletal muscle mass, is independently associated with poor survival in patients who receive chemotherapy for metastatic gastric cancer.

\section{Acknowledgements}

We are grateful to Dr Kenta Murotani, Center for Advanced Medicine and Clinical Research, Nagoya University Hospital, for his expert assistance in statistical analyses. This study was partly supported by JSPS KAKENHI grant number 2646026.

\section{References}

1. Prado CM, Lieffers JR, McCargar LJ, Reiman T, Sawyer MB, Martin L and Baracos VE: Prevalence and clinical implications of sarcopenic obesity in patients with solid tumours of the respiratory and gastrointestinal tracts: A population-based study. Lancet Oncol 9: 629-635, 2008.

2. Peng P, Hyder O, Firoozmand A, Kneuertz P, Schulick RD, Huang D, Makary M, Hirose K, Edil B, Choti MA, et al: Impact of sarcopenia on outcomes following resection of pancreatic adenocarcinoma. J Gastrointest Surg 16: 1478-1486, 2012.

3. Harimoto N, Shirabe K, Yamashita YI, Ikegami T, Yoshizumi T, Soejima Y, Ikeda T, Maehara Y, Nishie A and Yamanaka T: Sarcopenia as a predictor of prognosis in patients following hepatectomy for hepatocellular carcinoma. Br J Surg 100: 1523-1530, 2013.

4. van Vledder MG, Levolger S, Ayez N, Verhoef C, Tran TC and Ijzermans JN: Body composition and outcome in patients undergoing resection of colorectal liver metastases. Br J Surg 99: 550-557, 2012.

5. Lanic H, Kraut-Tauzia J, Modzelewski R, Clatot F, Mareschal S, Picquenot JM, Stamatoullas A, Leprêtre S, Tilly H and Jardin F: Sarcopenia is an independent prognostic factor in elderly patients with diffuse large B-cell lymphoma treated with immunochemotherapy. Leuk Lymphoma 55: 817-823, 2014.

6. Tan BH, Birdsell LA, Martin L, Baracos VE and Fearon KC: Sarcopenia in an overweight or obese patient is an adverse prognostic factor in pancreatic cancer. Clin Cancer Res 15: 6973-6979, 2009.

7. Goodpaster BH, Park SW, Harris TB, Kritchevsky SB, Nevitt M, Schwartz AV, Simonsick EM, Tylavsky FA, Visser M and Newman AB: The loss of skeletal muscle strength, mass, and quality in older adults: The health, aging and body composition study. J Gerontol A Biol Sci Med Sci 61: 1059-1064, 2006.

8. Goodpaster BH, Kelley DE, Thaete FL, He J and Ross R: Skeletal muscle attenuation determined by computed tomography is associated with skeletal muscle lipid content. J Appl Physiol (1985) 89: 104-110, 2000.

9. Delmonico MJ, Harris TB, Visser M, Park SW, Conroy MB, Velasquez-Mieyer P, Boudreau R, Manini TM, Nevitt M, Newman AB, et al; Health, Aging, and Body: Longitudinal study of muscle strength, quality, and adipose tissue infiltration. Am J Clin Nutr 90: 1579-1585, 2009.

10. Martin L, Birdsell L, Macdonald N, Reiman T, Clandinin MT, McCargar LJ, Murphy R, Ghosh S, Sawyer MB and Baracos VE: Cancer cachexia in the age of obesity: Skeletal muscle depletion is a powerful prognostic factor, independent of body mass index. J Clin Oncol 31: 1539-1547, 2013.

11. Antoun S, Lanoy E, Iacovelli R, Albiges-Sauvin L, Loriot Y, Merad-Taoufik M, Fizazi K, di Palma M, Baracos VE and Escudier B: Skeletal muscle density predicts prognosis in patients with metastatic renal cell carcinoma treated with targeted therapies. Cancer 119: 3377-3384, 2013.

12. Prado CM, Baracos VE, McCargar LJ, Reiman T, Mourtzakis M, Tonkin K, Mackey JR, Koski S, Pituskin E and Sawyer MB: Sarcopenia as a determinant of chemotherapy toxicity and time to tumor progression in metastatic breast cancer patients receiving capecitabine treatment. Clin Cancer Res 15: 2920-2926, 2009.

13. Antoun S, Baracos VE, Birdsell L, Escudier B and Sawyer MB: Low body mass index and sarcopenia associated with doselimiting toxicity of sorafenib in patients with renal cell carcinoma. Ann Oncol 21: 1594-1598, 2010.

14. Koizumi W, Narahara H, Hara T, Takagane A, Akiya T, Takagi M, Miyashita K, Nishizaki T, Kobayashi O, Takiyama W, et al: S-1 plus cisplatin versus S-1 alone for first-line treatment of advanced gastric cancer (SPIRITS trial): A phase III trial. Lancet Oncol 9: 215-221, 2008.

15. Mitsiopoulos N, Baumgartner RN, Heymsfield SB, Lyons W, Gallagher D and Ross R: Cadaver validation of skeletal muscle measurement by magnetic resonance imaging and computerized tomography. J Appl Physiol (1985) 85: 115-122, 1998.

16. Yamaoka Y, Fujitani K, Tsujinaka T, Yamamoto K, Hirao M and Sekimoto M: Skeletal muscle loss after total gastrectomy, exacerbated by adjuvant chemotherapy. Gastric Cancer 18: 382-389, 2015.

17. Abdiev S, Kodera Y, Fujiwara M, Koike M, Nakayama G, Ohashi N, Tanaka C, Sakamoto J and Nakao A: Nutritional recovery after open and laparoscopic gastrectomies. Gastric Cancer 14: 144-149, 2011. 